\title{
Translocation 21q22q in an infertile human male
}

\author{
A C CHANDLEY*, T B HARGREAVE $\dagger$, AND J M FLETCHER* \\ From * the MRC Clinical and Population Cytogenetics Unit and $\dagger$ the University of Edinburgh, \\ Department of Surgery (Urology), Western General Hospital, Edinburgh EH4 $2 X U$.
}

SUMMARY Details are given of a balanced 21q22q Robertsonian translocation ascertained through infertility in a phenotypically normal male. Chromosome analyses on the proband and his parents showed that the translocation arose as a new mutation. The patient was oligospermic and had a high frequency of morphological abnormalities in his spermatozoa. Meiotic investigations showed a chain trivalent in all primary spermatocytes examined at diakinesis/metaphase $\mathrm{I}$. The testicular histology was normal.

Robertsonian translocations involving chromosomes 21 and 22 in man are extremely rare. None was reported among 54749 unselected newborn infants karyotyped in seven major chromosome surveys around the world. ${ }^{1}$

Balanced $21 \mathrm{q} 22 \mathrm{q}$ translocations are invariably ascertained through a proband with translocation trisomy 21 Down's syndrome, about eight reports of familial inheritance of a t(21q22q) having been published. ${ }^{2-9}$

We report here a de novo balanced $t(21 q 22 q)$ ascertained through infertility in a phenotypically normal male. A careful search of published reports has failed to reveal any previous case of $t(21 \mathrm{q} 22 \mathrm{q})$ ascertained in this way.

\section{Case report}

The patient (MRC Registry No PK604/3/82), a 27year-old labourer, had been married for 7 years when he presented at the Infertility Clinic of the Western General Hospital, Edinburgh in September 1981. He and his wife had been trying for a child for 4 of those 7 years. Except for his infertility he was otherwise well. At the time of his birth his mother was 25 and his father 24 . He has two brothers, both of whom are married with children, and three sisters, two married with children and the third married but childless. A fourth sister died in infancy at 4 months, the death certificate recording 'marasmus' as the cause of death. His height was $172 \mathrm{~cm}$ and weight $61 \mathrm{~kg}$. Both testes were of normal size and consistency and the penis and scrotum were normally developed.

Received for publication 5 April 1982

\section{Seminal analysis}

Three semen samples, taken after intervals of 4 and 6 weeks respectively, gave sperm counts of $4 \times 10^{6}$, $8 \times 10^{6}$, and $1 \times 10^{6} / \mathrm{ml}$. The mean sperm count was $4.3 \times 10^{6} / \mathrm{ml}$. This compares with a mean count of $100 \times 10^{6} / \mathrm{ml}$ for men of normal fertility. ${ }^{10}$ Percentage motility for the three specimens was $50 \%, 10 \%$, and $0 \%$ respectively. Accurate analysis of sperm morphology was difficult because of the low density, but was carried out on the first seminal sample and showed that only $27 \%$ of spermatozoa were of normal form. This compares with a mean percentage of $79 \%$ for men of normal fertility. ${ }^{11}$ The most common types of defect found were 'dense heads' and 'immature forms' (table). Values of LH, FSH, and testosterone were all within normal limits and the trayside agglutination test and microimmobilisation test for antisperm antibody were negative for both semen and seminal plasma.

TABLE Analysis of sperm morphology in the patient.

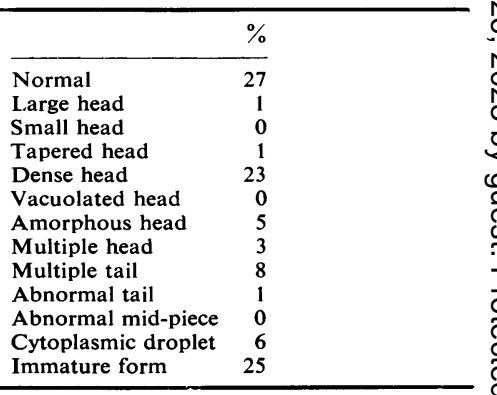




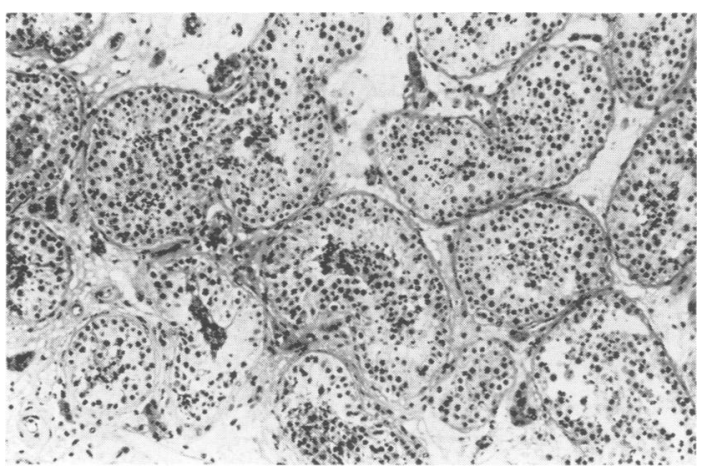

FIG 1 Testicular histology in the patient.

\section{Testicular histology}

During the course of investigations into the infertility of the patient, operation for the removal of a testicular biopsy was performed. The histological section of the testis showed a normal germinal epithelium with meiotic activity up to the stage of spermatozoan formation (fig 1). There was some tendency to sloughing of the epithelium into the central portion of the tubules. The only other feature of the biopsy was the presence of an increased amount of interstitial connective tissue focally. This appeared to be engulfing and surrounding some of the testicular tubules, but even in these tubules the germinal epithelium appeared to have survived and meiotic activity was seen. No inflammatory changes were present and there was no thickening of the tunica propria or of the basement membrane. The Leydig cells were not prominent but appeared to be well represented. The biopsy was classified, according to our own system of classification, as grade $I,{ }^{12}$ a category indicating normal testicular histology.

\section{Cytogenetic analysis}

\section{SOMATIC CHROMOSOMES}

Chromosome analyses on peripheral blood lymphocytes from the patient, his mother, and his father were performed. A total of $30 \mathrm{G}$ banded cells from the proband was analysed and all showed the 21q22q translocation, two missing $\mathrm{G}$ group chromosomes having been replaced by a metacentric chromosome, similar in size to an $\mathrm{F}$ group chromosome. $\mathrm{C}$ banded preparations indicated that the $21 \mathrm{q} 22 \mathrm{q}$ translocation formed by centric fusion was monocentric. The karyotype was interpreted as $45, X Y, t(21 q 22 q)$.

The mother and father had normal karyotypes, a $Q$ band analysis of inherited polymorphisms in the father and proband giving positive proof of paternity (K E Buckton, 1982, personal communication). Thus it appeared that the rearrangement had arisen de novo in a parental germ cell.

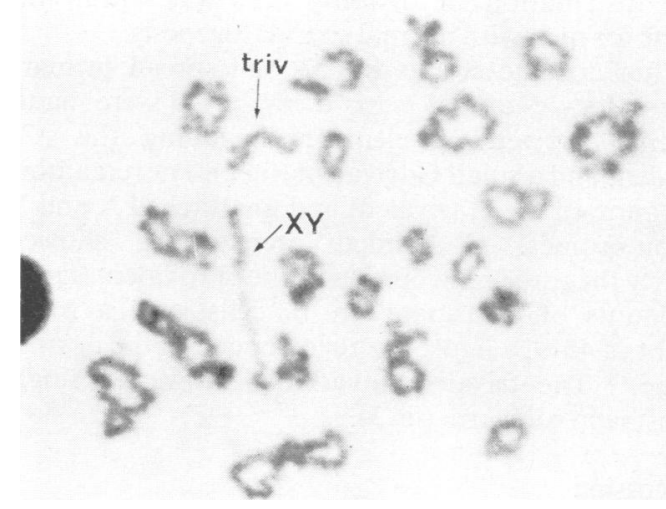

FIG 2 Primary spermatocyte at diakinesis showing the $21 q 22 q$ trivalent (triv). (Air dried preparation.)

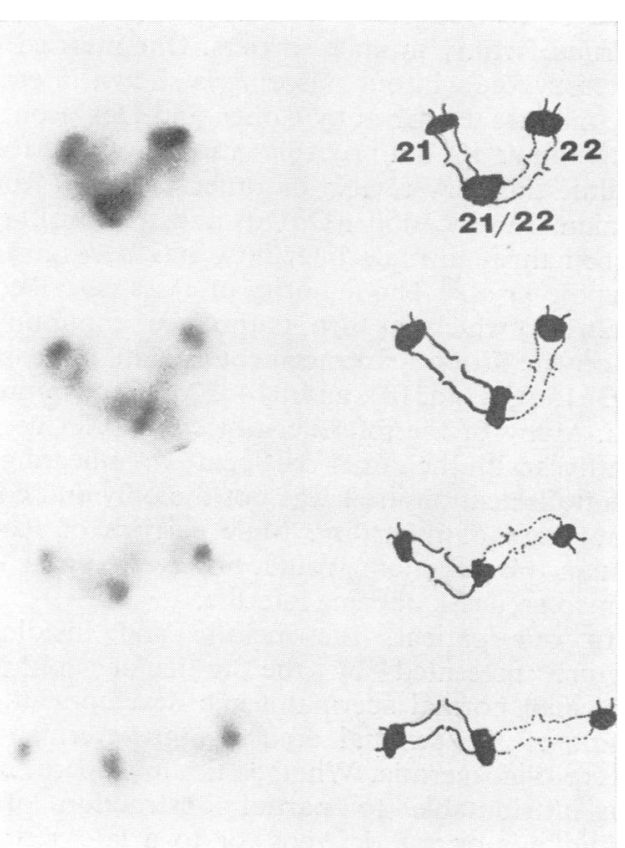

FIG 3 Cut out trivalents from four different primary spermatocytes ( $C$ banded preparations). Each shows a single chiasma in each arm. 
MEIOTIC CHROMOSOMES

Examination of the meiotic chromosomes was carried out on carbol-fuchsin stained air dried preparations. A distribution count of 100 dividing cells in the testicular suspension gave the following proportions: spermatogonial mitoses (14\%), meiotic metaphase I (36\%), meiotic metaphase II (50\%). The distribution of dividing cells was within the limits for men with normal spermatogenesis.

Chromosome counts on 22 well spread primary spermatocytes at diakinesis/metaphase I were made. Twenty showed 22 elements including the XY bivalent and a small $\mathrm{G}$ trivalent (fig 2). The remaining two showed the $G$ trivalent and unattached $X$ and $Y$ chromosomes. $\mathrm{C}$ banded preparations showed clearly the three centromeres of the $G$ trivalent (fig 3).

Counts of chiasmata on 10 cells gave a mean count of $45 \cdot 9$, a figure at the lower end of the normal range. ${ }^{13}$ The trivalent invariably showed a single chiasma in each arm (fig 3).

\section{Discussion}

There would appear to have been no previous cases of balanced $21 \mathrm{q} 22 \mathrm{q}$ translocation ascertained through infertility in a male. From a review of the $t(21 q 22 q)$ pedigrees published, it seems that this type of rearrangement is usually compatible with normal fertility in male carriers. One married male heterozygote without offspring is shown in each of the families described by Cohen and Davidson ${ }^{4}$ and Buckton et al, ${ }^{9}$ but no explanation is offered for the childlessness. A review of other types of Robertsonian translocation $\mathrm{t}(\mathrm{DqDq})$ and $\mathrm{t}(\mathrm{DqGq})$, ascertained through male infertility, has been given by Tiepolo et al. ${ }^{14}$ The majority of cases described are $t(13 q 14 q)$ which, in turn, is the most common type of centric fusion rearrangement in man, but cases of $t(13 q 15 q), t(14 q 21 q)$, and $t(14 q 22 q)$ are also presented. Many of the infertile subjects had fertile male relatives with the same translocation, indicating that the translocation itself was not the only and consistent cause of infertility. Male carriers of Robertsonian translocations would, however, appear to be at increased risk of being infertile.

In our patient, the meiotic and histological picture presented by the testicular epithelium indicated normal spermatogenic development. The result of the seminal analyses, however, showed severe oligospermia. Whether the low sperm count was attributable to partial obstruction of the epididymis or vas deferens, or to a late germ cell maturation failure, perhaps related to the chromosomal anomaly, cannot be resolved. The increase in connective tissue which was seen, from the histological specimen of testis, to be engulfing and surrounding some of the seminiferous tubules might $\stackrel{\stackrel{\mathbb{P}}{.}}{\stackrel{4}{*}}$ indicate a partial obstruction in the area of vasa efferentia, although this is considered unlikely as there was no induration of the epididymides or any other abnormality of note in either epididymis. $\overline{\bar{c}}$ Moreover, antisperm antibodies were not detected $\vec{\phi}$ whereas they frequently are in obstructed cases. The $\varrho$ trauma to which the patient would have been os subjected in order to confirm a diagnosis of obstruc- $\overrightarrow{0}$ tion was not considered justifiable, however, since it was felt that little or no improvement in the condition $\vec{\omega}$ could have been made by surgical intervention.

The alternative possibility that the patient had a late failure in spermatozoan development, associated with his chromosome abnormality, must also be or considered. An association between spermatogenic $\omega$ impairment and a Robertsonian rearrangement $\sigma$ would not be unprecedented. Varying degrees of 음 spermatogenic impairment have been reported $\rightarrow$ among carriers of both DqDq and DqGq translocations, ${ }^{15-18}$ but the spermatogenic arrest observed has generally been in the spermatocyte or spermatid stages. On the other hand, the spermatogenic failure may be unrelated to the chromosome anomaly, but of some alternative aetiology.

The high frequency of morphological abnormalities among the spermatozoa of the patient might be associated directly with heterozygosity for the translocation since there is no reason, per se, why obstruction should alter sperm morphology. High frequencies of morphologically abnormal spermatozoa in patients both with $t(D q D q)$ and $t(D q G q)$ rearrangements have been reported previously. ${ }^{15} 1819$

The combined effects of a low sperm count and high numbers of sperm morphological abnormalities would appear, however, to offer the patient a poor prognosis for fertility. Were he ever to make his wife pregnant, consideration would have to be given to the risk of his producing an offspring with translocation trisomy 21 Down's syndrome. Such a risk would appear, however, to be small. Chapman et al, ${ }^{7}$ from published data on families in which a $21 q 22 q$ translocation is segregating, have calculated that the risk to a female carrier is $0.0684 \pm 0.0270$, while that to a male carrier is probably much smaller, with an upper limit of 0.0286 . Except for two probands none of the 70 children of carrier fathers had Down's syndrome. Any pregnancy which might ensue for the patient and his wife, however unlikely, will, nevertheless, be carefully monitored.

The authors wish to thank Dr A Busuttil, Consultant Pathologist, Western General Hospital, for the testicular histology report. Dr Marjorie Newton is thanked for the collection of blood samples, and the staff of the Registry of the MRC Clinical and 
Population Cytogenetics Unit are thanked for pedigree information. The contribution of Dr Litsa Theodorou in the analysis of the meiotic chromosomes is also acknowledged.

\section{References}

1 Nielsen J, Sillesen I. Incidence of chromosome abberrations among 11,148 newborn children. Humangenetik $1975 ; 30: 1-12$.

2 Shaw M. Familial mongolism. Cytogenetics 1962;1:14179.

${ }^{3}$ Pfeiffer RA. The transmission of $\mathrm{G} / \mathrm{G}$ translocation. Lancet $1963 ; \mathbf{i}: 1163$.

4 Cohen MM, Davidson RG. Down's syndrome associated with a familial $(21 \mathrm{q}-; 22 \mathrm{q}+)$ translocation. Cytogenetics 1967;6:321-30.

5 Jackson JF, Ashford WP. Familial mongolism due to 21/22 chromosome translocation. JAMA 1967;200:722-4.

6 Yang SJ, Rosenberg S. 21/22 translocation Down's syndrome: a family with unusual segregating patterns. Am J Hum Genet 1969;21:248-51.

7 Chapman CJ, Gardner RJM, Veale AMO. Segregation analysis of a large $\mathrm{t}(21 \mathrm{q} 22 \mathrm{q})$ family. J Med Genet 1973; $10: 362-6$.

8 Zergollern L. Three generations and seven family members with a t(21q22q) chromosome. J Med Genet 1974; 11:379-81.

9 Buckton KE, Newton MS, Lauder IJ, de Mey R, Elliot D, Skinner R. Familial transmission of a (21q22q) translocation. Cytogenet Cell Genet 1975;15:103-11.

10 MacLeod J, Gold RZ. The male factor in fertility and infertility. II. Spermatozoon counts in 1000 men of known fertility and in 1000 cases of infertile marriage. $J$ Urol $1951 ; 66: 436-69$.
11 MacLeod J, Gold RZ. The male factor in fertility and infertility. IV. Sperm morphology in fertile and infertile marriage. Fertil Steril $1951 ; 2: 394-414$.

12 Chandley AC, Maclean N, Edmond P, Fletcher J, Watson GS. Cytogenetics and infertility in man. II. Testicular histology and meiosis. Ann Hum Genet 1976; 40:165-76.

13 Paris Conference (1971). Standardization in human cytogenetics. Birth Defects 1972;VIII.

14 Tiepolo L, Zuffardi O, Fraccaro M, Giarola A. Chromosome abnormalities and male infertility. In: Frajese G, Hafez ESE, Conti C, Fabbrini A, eds. Oligozoospermia: recent progress in andrology. New York: Raven Press, 1981.

$15 \mathrm{Kjessler} \mathrm{B.} \mathrm{Karyotype,} \mathrm{meiosis} \mathrm{and} \mathrm{spermatogenesis} \mathrm{in} \mathrm{a}$ sample of men attending an infertility clinic. Monographs in human genetics. Vol 2. Basel: Karger, 1966.

16 Dutrillaux B, Le Lorier G, Salat J, Rotman J. Incidences des anomalies chromosomiques dans la stérilité masculine. Presse Med 1971;79:1231-4.

17 Skakkebaek N, Hultén M, Philip J. Quantification of human seminiferous epithelium. IV. Histological studies in 17 men with numerical and structural autosomal aberrations. Acta Path Microbiol Scand 1973;81:112-24.

18 Chandley AC, Edmond P, Christie S, Gowans L, Fletcher J, Frackiwicz A, Newton M. Cytogenetics and infertility in man. I. Karyotype and seminal analysis. Ann Hum Genet 1975;39:231-54.

${ }^{19}$ Hultén $M$, Lindsten $J$. The behaviour of structural aberrations at male meiosis: information from man. In: Jacobs PA, Price WH, Law P, eds. Human population cytogenetics. Pfizer Medical Monographs No 5. Edinburgh: Edinburgh University Press, 1970.

Requests for reprints to Dr A C Chandley, MRC Clinical and Population Cytogenetics Unit, Western General Hospital, Edinburgh EH4 2XU. 